\title{
Perfection of the Electrochemical Method of Sewage Treatment
}

\author{
Nikolai P. Shapkin, Eugene K. Papynov, Irina G. Halchenko, Nellie N. Zhamskaya, \\ Svetlana A. Katkova, Olga A. Apanasenko \\ Far Eastern State University, Vladivostok, Russia \\ E-mail:khalch@mail.ru \\ Received May 15, 2010; revised June 7, 2010; accepted June 15, 2010
}

\begin{abstract}
Problems of the given research are to study the dependence of electrochemical oxidation degree, sewage disinfecting and a filtration of the fish-processing enterprises against time in the presence of sea water. Given tasks are solved by means of sewage processing in static electroflotate with titanic modified ORTA (the orta-ruteniego-titanic anode) by sea water adding of a certain concentration as coagulator.
\end{abstract}

Keywords: Sea Water, Coagulation, Modified Orra, Electrochemical Oxidation

\section{Introduction}

Now days an actual environmental problem is clearing and recycling of sewage, formed at various stages of technological processes of the enterprises. Pollutants continue to arrive in water objects, despite of all measures and the methods applied to sewage treatment. The most dangerous pollutants are heavy metals (HM) and organic substances (fibers, fats, dyes etc.).

Last years the tendency of physical and chemical modernization of methods of sewage treatment of the food enterprises from albumens with the aim of their recycling as valuable additives of animals, birds, and fishes forage [1] was outlined. The choice of the sewage clearing scheme of any enterprise depends on many factors: sewage quantities, economic expediency of admixture extraction from sewage, requirements to quality of the cleared water with the purpose of using it in the systems of water supply circulating.

The technology of the household sewage clearing, is based on sea water using, according to it the device for liquid waste dumping into the sea is applied; the containing of the pipeline for liquid waste giving to land station, located on seacoast, and the by-pass pipe which is located on a sea-bottom to rock the sea water into the pool in which there the mixing of a waste with sea water in the set parity [2] is known. Absence of disinfecting system and low degree of drains clearing is the deficiency of this method.

The way of sewage treatment including coagulation of albumenous products with anode oxidation usage and its subsequent branch coagulate [3] is also known. The process is carried out in two stages to increase the degree of clearance. The way concerns sewage of potato-starch manufactures. However this way does not satisfy sewage treatment requirements of fish processor enterprises. Since, the chemical compound of sewage from processing of hydrobionts is more combined; it is impossible to achieve sufficient clearance from inorganic admixture and lipid contained components in the known way.

There is the technology of sewage treatment of textile factory with use of electrochemical processing with an iron or aluminum electrode and its further additional clearance by polymer [4]. But this technology was not applied for clearing of the food enterprises waters. Also declared degree of clearance is not sufficient and makes $70-80 \%$.

The closest way by technical essence is the way of sewage treatment of fish manufactures by means of sewage processing in electroflotate with ferrous-coal electrodes, with usage of sodium chloride as coagulate and further subsequent additional cleaning by means of the activated form of tseolite [5]. However the known way demands a considerable quantity of the coagulator and the clearing percent after electro oxidation is insufficiently high and makes no more than $70 \%$.

\section{Material and Methods}

Problems of the given research are to study the dependence of electrochemical oxidation degree, sewage disinfecting and a filtration of the fish-processing enterprises 
against time in the presence of sea water. Given tasks are solved by means of sewage processing in static electroflotate with titanic modified ORTA (the orta-ruteniegotitanic anode) by sea water adding of a certain concentration as coagulator.

The influence of time and sea water concentration on coagulation and electro oxidation process on sewage was investigated by us. Sizes of TOC with different concentration of sea water with ORTA were compared to define optimum conditions of clearing at different stages of process.

Sea water is effective sediment of a great number colloidal and dissolved organic pollutants on the account of the high maintenance of magnesium salts and calcium which easily remove a charge of colloidal particles and give low dissolved connections with a great number of polluting substances (anion organic and inorganic acids). Besides, the high maintenance of chlorides in sea water allows receiving at certain potential with sufficient concentration a gipohlorit-ion which is an effective oxidizer of organic and inorganic pollutants.

\section{Results-Discussion}

Results of studying of coagulation conditions of real sewage fish processing enterprises by sea water are presented graphically (rice 1,2).

From the presented dependences it is visible that optimum concentration of sea water is concentration of $35 \%$ and coagulation time is 90 minutes.

In the result it was established that the maximum degree of clearing is reached under condition of the maintenance in electroflotate of $35 \%$ of sea water solution and time of carrying out of electro flotation of 90 minutes. At higher parametres clearing degree does not increase. Therefore the further researches were carried out under these chosen conditions.

Results of clearing of real sewage of fish processing enterprises with $35 \%$ concentration of sea water and an electrode for electro flotation ORTA are presented graphically on Figure 3.

The clearing percent $(\%$ ХПК) has made $92 \%$.

\section{Conclusions}

Having analyzed the obtained data, it is possible to make the conclusion about expediency of clearing and disinfecting of albumin contained sewage of the food enterprises by means of their mixing with sea water (concentration of $35 \%$ ) in the electro flotation with application of ORTA-IRON electrodes within 90 minutes. As a result, TOC decreases on $92-96 \%$.

After processing of sewage by electro flotation, sediments and denaturized fibers, salts carbon and inorganic

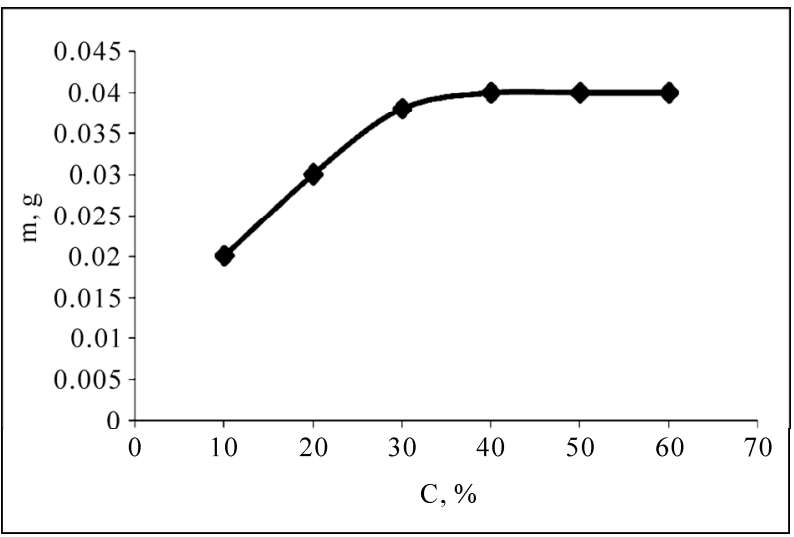

Figure 1. Dependence of weight of sediment on concentration of sea water.

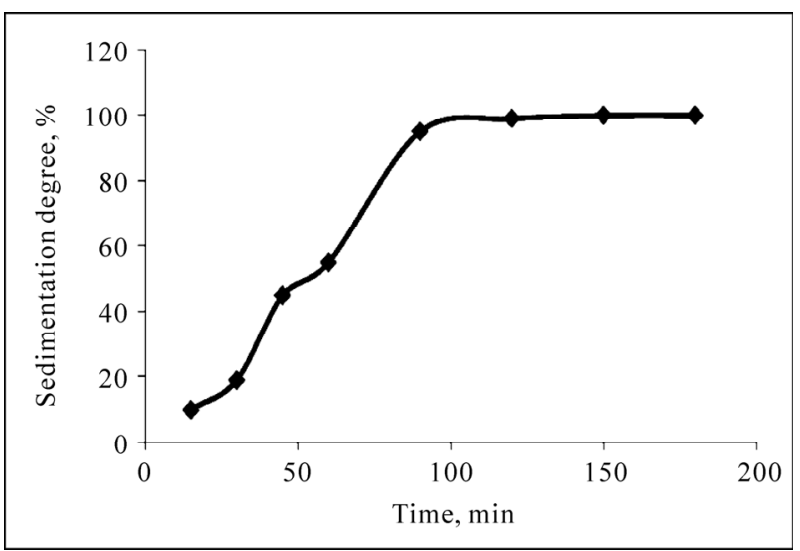

Figure 2. Dependence of degree of sedimentation on time of carrying out of coagulation.

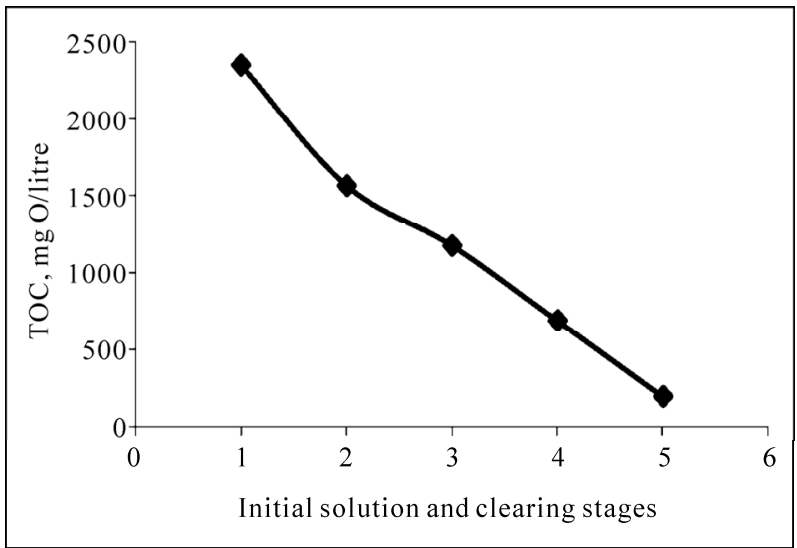

Figure 3. Meaning of TOC of an initial solution and change of TOC at different stages of clearing of real sewage with $35 \%$ sea water concentration and an electrode for electro flotation ORTA.

acids are formed by electro oxidation, according to the element analysis data, and spectroscopy

In IR sediment specter (Figure 4), allocated after electrochemical processing of waste and modeling water is 


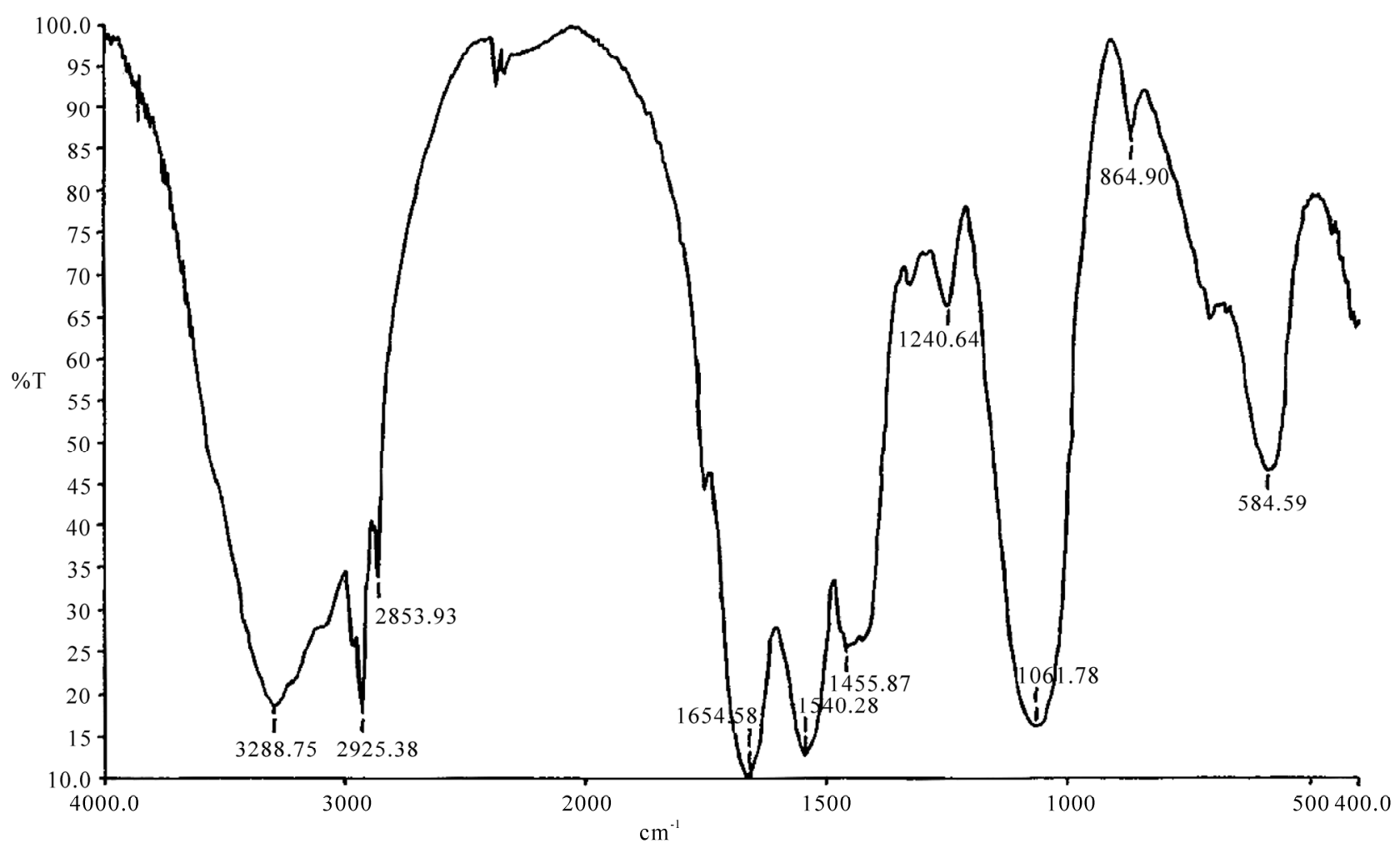

Figure 4. IR-spectrum of the deposit allocated after electrochemical processing of sewage.

observed a few distinctive strips of absorption, just strips: 2924, $2853 \mathrm{sm}^{-1}$-appropriated to valency fluctuations of the connection $\mathrm{C}-\mathrm{H}, 3400-3200 \mathrm{sm}^{-1}$-appropriated to valency fluctuations $\mathrm{O}-\mathrm{H}, \mathrm{N}-\mathrm{H}$ connections, $1710 \mathrm{sm}^{-1}-$ appropriated to valency fluctuations of connection $\mathrm{C}=\mathrm{O}$ in carbuncled group, 1630-1650 $\mathrm{sm}^{-1}$-to valency fluctuations in $\mathrm{C}=\mathrm{O}$ in carbonated connections, $1549 \mathrm{sm}^{-1}$-to deformational fluctuations $\mathrm{N}-\mathrm{H}, \mathrm{O}-\mathrm{H}, 1465,1403 \mathrm{sm}^{-1}-$ to deformational fluctuations $\mathrm{C}-\mathrm{H}, 1150 \mathrm{sm}^{-1}, 1096 \mathrm{sm}^{-1}-$ to valency fluctuations $\mathrm{C}-\mathrm{O}$ in ethereal fragments.

Chlorine is absent after washing of sediments by the distilled water, while before washing by water the chlorine maintenance fluctuated in limits from 1 to $2 \%$.

After electrochemical processing real and modeling sewage were extricated by hexan which does not contain chloride-organic connections. The Chromatographic analysis of extracts has shown the absence of any chloride-organic connections. Thus, it is possible to assert that at electrochemical influence on formation drains of chloride-organic connections does not occur.

Use of the received results is possible in already existing clearing of household sewage technologies of small enterprises, and as clearings of the fish-processing enterprises drains.

\section{References}

[1] O. B. Ivanchenko and R. E. Habibullin, "An Estimation Toxic Potential of Sewage Meat Processing Enterprises/ News of High Schools," Food Technology, No. 4. 2005, pp. 61-63.

[2] D. Michael, V. Foglia and G. Facon, "Device for Dumping at Sea of Sewage," The Patent of France.

[3] T. V. Mgebrishvili, M. F. Tseraidi, J. N. Pankov, K. Haylsher, A. P. Mordovin and V. G. Kovalenko, "Method of Sewage Purification," The Patent of the Russian Federation, 1997.

[4] A. E. Wilcock, M. Brewster and G. Peck, "Environmental Chemistry of Dyes and Pigments," A. Reife and H. S. Freeman, Eds., John Wiley \& Sons, Ink., New York, 1996.

[5] N. P. Shapkin and N. N. Zhamskaya, "Method of Sewage Purification," The Patent of the Russian Federation, 1998. 